\title{
Islas hermanas: La Palma y Cuba a finales del siglo XIX (1875-1900)
}

\author{
Ángel Dámaso Luis León
}

\section{OpenEdition}

\section{Journals}

Edición electrónica

URL: https://journals.openedition.org/cher/476

DOI: $10.4000 /$ cher.476

ISSN: 2803-5992

\section{Editor}

Presses universitaires de Strasbourg

\section{Edición impresa}

Fecha de publicación: 10 junio 2021

Paginación: 63-82

ISBN: 9791034400928

ISSN: 1968-035X

\section{Referencia electrónica}

Ángel Dámaso Luis León, «Islas hermanas: La Palma y Cuba a finales del siglo xIx (1875-1900)», reCHERches [En línea], 26 | 2021, Publicado el 15 septiembre 2021, consultado el 17 noviembre 2021. URL: http://journals.openedition.org/cher/476 ; DOI: https://doi.org/10.4000/cher.476 


\title{
Islas hermanas: La Palma y Cuba a finales del siglo XIX (1875-1900)
}

\author{
Ángel Dámaso Luis LeóN*
}

Docos lugares tienen una conexión histórica tan fuerte con la isla de Cuba como las islas Canarias, y entre ellas, la isla de La Palma. Desde la tradición del ron y el tabaco hasta las más conocidas celebraciones populares, en la Isla casi todo tiene un cierto aroma a Cuba. Por ello, este trabajo busca analizar cómo reflejaba la prensa palmera de finales del siglo XIx los procesos que se estaban dando entre los dos lados del océano Atlántico ${ }^{1}$.

En la búsqueda de ese objetivo, se analizarán los discursos hegemónicos que aparecían en los rotativos publicados en la Isla durante ese segmento de tiempo. Para ello, se estudiarán casi veinticinco cabeceras diferentes, muchas plurianuales, que aún se conservan en la actualidad en diversas instituciones y portales ${ }^{2}$. La totalidad de esas cabeceras estudiadas tendrán origen santacrucero, sabemos de efímeras publicaciones periódicas que fueron publicadas en otras localidades de la Isla durante este segmento, pero que no se han conservado. Ello nos plantea una limitación: a pesar de que Santa Cruz de La Palma, La Ciudad, como era llamada en aquel entonces, era el centro neurálgico de la Isla, estos periódicos no reflejarán por igual el pensamiento de la burguesía de toda la Isla, sino que habrá un marcado sesgo capitalino.

* Ángel Dámaso Luis León, Universidad de La Laguna. ORCID:0000-0003-1311-9679, $<$ aluisleo@ull.edu.es>.

1 Este estudio forma parte del Proyecto de Investigación "El orden y sus desafíos en el Circuncaribe hispano, 1791-1960” (MICINN RTI2018-094305-B-100).

2 La inmensa mayoría de las cabeceras han sido consultadas en la Real Sociedad Cosmológica de Santa Cruz de La Palma (un 54,2\%), seguido del portal Jable. Archivo de Prensa Digital de la Universidad de Las Palmas de Gran Canaria (25\%), la Hemeroteca del Fondo Canarias de la Biblioteca General y de Humanidades de la Universidad de La Laguna (12,5\%) y el portal Prensa Canaria Digitalizada, también perteneciente a la Universidad de La Laguna (8,3\%). Dicho lo cual, este es un cálculo relativo de las cabeceras, no de los números totales consultados, los cuales darían unos resultados diferentes. 
Otro de los límites que debe ser tenido en cuenta es que la prensa es una fuente parcial (como cualquier otra) que refleja los intereses de sectores determinados, en este caso, de la burguesía palmera. También se debe tener en cuenta que la difusión de la información que estos periódicos publicaban es ciertamente limitada por una cuestión esencial: los altos niveles de analfabetismo en el Archipiélago, que se encontraban en el 79,8 \% del total de la población para 1887 (González Pérez 1996: 328). Dicho lo cual, no podemos, ni pretendemos, hacer un discurso totalizador y completo de cómo se articulaba el imaginario colectivo palmero sobre Cuba en esta época, pero sí se busca sumar una pieza más que ayude a construir ese complejo puzle. En palabras de Almuiña Fernández (1977: 710): "no se trata de magnificar ningún tipo documental en concreto», pero sí de valorar, en su justa medida, lo que puede aportar una fuente tan rica como la prensa, sobre todo para conocer el pensamiento de la burguesía palmera de aquel entonces.

El marco del trabajo queda claramente definido geográfica y temporalmente. El objeto de estudio será La Palma, primero, por su vinculación presente, pero también por su encaje en el pasado. Dentro de la dinámica general canaria, se busca observar y comparar si la red tejida entre La Palma y Cuba es, simplemente un hilo más en la madeja colectiva canaria o si, en cambio, y como se plantea en la hipótesis central, hay una suerte de relación especial o, al menos, cuantitativamente significada.

El límite temporal del estudio será el último cuarto del siglo xix. Se ha escogido este segmento porque hace coincidir el auge portuario de Santa Cruz de La Palma con el período de emigración masiva de canarios a Cuba. Siendo más concretos, este proceso migratorio se daría desde la década de los ochenta, con la eliminación progresiva en la Antilla de todo lo relacionado con la esclavitud, pero se ha decidido redondear el proceso a una fecha más amplia que permita situar un poco mejor la experiencia. En ese contexto, se analizará cómo la prensa observa tres aspectos en concreto: la emigración, el comercio y la guerra, haciendo hincapié principalmente en los dos primeros. También se hará un análisis comparado con respecto a otros territorios americanos. En este sentido, resulta oportuno aclarar que la cuestión de la guerra se tocará relativamente poco, porque este artículo posee lógicas limitaciones de extensión y es una cuestión que, en sí misma, daría para uno propio. Por ello, se abordarán cuestiones relacionadas con la línea central del resto del trabajo principalmente.

En definitiva, este trabajo se enmarcará dentro de la dinámica de los estudios insulares, los cuales han experimentado un fuerte crecimiento durante el último decenio y medio, intentando materializar lo que Godfrey Baldacchino (2006: 10) argumentó en sus inicios, acerca de «ver a las islas como parte de sistemas complejos y transversales de interacción regional y global», será ese el objetivo último de este trabajo: analizar cómo se observa la relación entre Cuba y La Palma y, sobre todo, cómo la misma propicia y ayuda a tejer otras redes nacionales e internacionales más intrincadas. 


\section{Emigración}

Si un fenómeno forma parte del día a día de la población palmera y canaria a finales del siglo xIx, ese es el de la emigración. La salida de hombres y mujeres con destino a América, en busca de un futuro mejor, se convertirá en una constante en este período. A pesar de lo que a primera vista pudiera parecer normal, y de lo que nos muestra la evidencia para otros lugares de Canarias (Luis León 2015: 4-6), entre la élite de la isla de La Palma no encontraremos una fuerte hostilidad hacia el emigrante, al menos con respecto hacia los que viajan a Cuba.

Las noticias sobre Cuba y sobre emigración serán de lo más variado y ocuparán diferentes posiciones según el periódico y el marco temporal concreto. La mayor parte de las cabeceras no exhibe una confrontación fuerte con este fenómeno masivo, es más, se muestran bastante comprensivos. Incluso, se pueden encontrar ejemplos de varios periódicos que justifican la emigración y le dan cierto aporte de normalidad. Un curioso artículo aparecido en el periódico El Iris defiende los legítimos deseos de los más pobres por mejorar sus condiciones de vida y considera injusto que se condene socialmente su lucha y se los tache de «ambiciosos vulgares», mientras que a los ricos sí que se les permite desarrollar todo su potencial vital. Además, argumenta que la única diferencia entre la ambición de los pobres y la de los ricos es que, probablemente, los primeros no puedan alcanzar sus objetivos por motivaciones que les son ajenas, mientras que los segundos sí que dependen solamente de sus propias actuaciones para tener éxito (El Iris... 02/04/1881: 1).

Este discurso propicio a la emigración no solo se restringe a esta noticia y a esta cabecera, habrá otros que se signifiquen en idéntico sentido. Por ejemplo, el periódico La Justicia publica a finales de siglo un artículo centrado en la emigración de los hijos de Tazacorte. Este periódico, además de reflejar que la mayoría de los bagañetes (gentilicio de la localidad) que viajan a Cuba lo hacen para emplearse en la agricultura del tabaco, se centra en la laboriosidad de los mismos a la hora de realizar sus funciones (La Justicia 20/07/1899: 1-2). Otros ejemplos que aparecen previamente pueden ser los publicados por José Eduardo Pérez Hernández (2003: 78), quien extrae los escritos periodísticos de Isaac Viera; literato, periodista y educador lanzaroteño que residió en La Palma. Viera menciona, en numerosas ocasiones, y en diferentes cabeceras, el buen hacer del emigrante palmero, que emigra normalmente hacia Cuba, donde trabaja duramente, y consigue retornar con una pequeña fortuna que empleará en sus propios pueblos, haciendo referencia a varios enclaves como El Paso o Mazo. En definitiva, nos encontramos con una realidad que no solo muestra a una élite que convive de manera positiva con la emigración del común, sino que, en casos concretos, llega incluso a exaltar la laboriosidad del emigrante palmero.

Esta defensa a de la emigración no quiere decir que se defienda la emigración de todo tipo. En primer lugar, hay una cuestión geográfica, se defiende la emigración hacia Cuba. Y, segundo y más importante, se defiende una emigración basada en un modelo prácticamente capitalista, de libre mercado. 
Algunas cabeceras previas al fin de la esclavitud en Cuba, como La Asociación o La Palma, hacen, en varias ocasiones, una crítica al modelo migratorio basado en la contrata ${ }^{3}$, el más duro y que, sin ninguna duda, está influenciado por el trato esclavista en retroceso con el que convive (De Paz y Hernández 1993: 57-97). Dicho lo cual, y a pesar de la dureza del fenómeno, en el período que abarca este estudio, el último cuarto de la centuria, el modelo de contrata se encuentra en su fase de senectud, y acabará por ser sustituido finalmente por un modelo de tipo capitalista, lo que hace que la publicación de este tipo de críticas se limite a las décadas de los setenta y ochenta.

En La Palma, no es extraño que existan voces que vinculen pobreza y emigración. Aunque, al no haber excesiva perturbación con el proceso migratorio, tampoco es un binomio que esté siempre presente en las diferentes publicaciones. En contraste con el caso de Tenerife, donde la emigración es prácticamente fruto, según los periódicos, de la codicia de los emigrados y de la falta de ocupación, sobre todo en obras públicas (Luis León 2015: 4-5); para La Palma, no habrá una petición generalizada de obras públicas que buscan, al menos, paliar el fenómeno migratorio ${ }^{4}$.

La prensa será fuente de noticias importantes. A pesar de los altos porcentajes de analfabetismo en las Islas, lo que producía que la capacidad comunicativa de estos periódicos fuera limitada, tenemos casos de periódicos que informan, por ejemplo, sobre herencias indianas que quedan sin reclamar en Cuba. Varios de los casos que se pueden rastrear muestran a palmeros que han fallecido en tierras cubanas y que han dejado pequeños terrenos o dineros cuyos herederos legítimos en territorio cubano se desconocen, por lo que se buscan posibles familiares que los reclamen en La Palma. Un caso concreto será el de un hombre originario de la Isla, que fallece en Cuba sin descendientes, por lo que el periódico La Palma (26/06/1877: 2) publicará la búsqueda de herederos.

Las informaciones de la actualidad cubana, que llegarán mayormente por medio de telégrafos ${ }^{5}$ e intermediarios durante la época que concierne a este estudio, serán habituales. Algunos emigrados enviarán cartas a las diferentes redacciones, donde muestran sus pareceres sobre la situación en Cuba, sobre La Palma, o sobre otras cuestiones. Esta información quedará recogida no solo en números ordinarios de los periódicos, sino también en otros de carácter extraordinario. Suplementos como el de La Nueva Palma traerán mucha información en cada número.

3 Pueden verse, por ejemplo: La Palma... 01/10/1878: 2; La Palma..., 24/10/1878: 1-2; La Asociación..., 16/10/1881: 1- .

4 De toda nuestra pesquisa, solo hemos podido encontrar un artículo publicado en $E l$ Fomento, en el que se dice que se necesitan obras públicas para «proporcionar trabajo al gran número de obreros que permanentemente se ven obligados a abandonar nuestro suelo» (El Fomento..., 08/10/1887: 1-2).

5 Para más información sobre el desarrollo del telégrafo en La Palma y Canarias, véase: Pérez Jiménez, 2015. 
En ese sentido, será habitual que se publiquen sucesos políticos y comerciales, pero también habrá cierta profusión de información acerca de episodios meteorológicos y geológicos adversos, tales como fuertes lluvias, inundaciones, desbordamiento de ríos, terremotos, etc. Los reportajes no eran exhaustivos, pero tampoco anecdóticos, se dan informaciones y ubicaciones de los mismos con relativa asiduidad, para que las personas con conexión con esos territorios puedan estar informadas, y se mencionan en muchas ocasiones los damnificados de estas situaciones adversas.

De la colonia que está instalada en Cuba no se reniega. Se recogen intentos de censos de habitantes de Santa Cruz de La Palma en Cuba, censos que principalmente recogen a personas pertenecientes a grupos privilegiados pero que, como en otros aspectos, transciende la división de clases. Como resulta lógico, estos periódicos sienten predilección por los miembros de la élite palmera, de los cuales, en algunas ocasiones, recogerán sus idas y venidas de la Antilla ${ }^{6}$. En las páginas de varios periódicos se recogen también los envíos monetarios que hacen diversos grupos de emigrados anónimos, e incluso asociaciones de canarios en Cuba (como la situada en la ciudad de Matanzas), para fines determinados, como los arreglos en iglesias o capillas, o para hacer frente a situaciones de necesidad tras episodios meteorológicos adversos que afecten al Archipiélago.

Durante la década de los setenta se irá produciendo un hecho creciente y significativo que se convertirá en tendencia generalizada durante el decenio siguiente: la publicación de las salidas y llegadas de los barcos que hacen la carrera americana, principalmente con destino a los puertos de Cuba. Por poner un simple ejemplo, en las ediciones del periódico La Patria de los meses de abril y mayo de 1877 (ocho números en total), aparecen hasta quince anuncios de llegadas y salidas producidas o por producir. En un número importante de estas menciones se intenta cuantificar el total de pasajeros que llegan al puerto de Santa Cruz de La Palma o que salen de él, el cual oscila entre unas pocas unidades, en algunos casos, y viajes donde se superan ampliamente las centenas de pasajeros. En otras ocasiones, sin mostrar ningún elemento que justifique la decisión, solo se menciona el nombre del barco, el día de salida o llegada y el destino o las posibles escalas.

Gran parte de esos barcos procedían de otras islas del Archipiélago, principalmente de los puertos de Las Palmas y de Santa Cruz de Tenerife, pero también había otros que procedían de otros puntos del territorio español, principalmente de puertos atlánticos. Un número importante realizaba la salida

6 Uno de los personajes que recibe esta especial atención sería Luis Felipe Gómez Wangüemert, uno de los padres del nacionalismo canario y fundador del Partido Nacionalista Canario, quien, durante su juventud, había sido ferviente defensor de la causa española en Cuba. En los periódicos se recogen diferentes acciones relacionadas con sus idas y venidas de Cuba, como la entrega de una bandera con la que habían luchado los españoles en la Guerra, al ayuntamiento de Los Llanos de Aridane (De Paz 1991: 29-30). Véase también: La Justicia..., 19/08/1899: 3. 
desde el propio puerto de Santa Cruz de La Palma, y hacían escala, mayormente, en puertos de la isla de Tenerife. También habrá algunos casos, pero menos habituales, que realizarán escalas en Las Palmas de Gran Canaria, en otros puertos de la isla de La Palma (en el norte o en Tazacorte), o incluso en San Sebastián de La Gomera, pero serán menos habituales que las escalas en Tenerife. La mayor parte de los barcos que salen o pasan por Santa Cruz de La Palma tendrán como destino último el puerto de La Habana, pero casi nunca será un destino único. Otros puertos cubanos como Gibara, Caibarien o Santiago serán paradas habituales. En otras ocasiones, el trayecto será internacional, conectando La Habana pero también otras ciudades como San Juan de Puerto Rico, La Guaira, en Venezuela, o Nueva York.

En los viajes de retorno también se observan situaciones similares, es decir, un esquema que raramente poseía un único trayecto lineal de origen a destino. Las escalas serán múltiples, ya fuera en Cuba, en Canarias o en otros lugares de la geografía mundial. Un buen ejemplo de esto es la información que aporta La Palma, que en sus páginas recoge la llegada a puerto de un buque con el nombre de Celaje. El Celaje había salido de La Habana con destino a Vigo, puerto donde se había encontrado también con el Triunfo, uno de los barcos habituales de la ruta canario-cubana. A su llegada a La Palma, los tripulantes del Celaje notificaron que el Triunfo saldría a los pocos días en dirección a Canarias, puesto que se encontraba en el puerto gallego realizando la habitual cuarentena marítima que realizaban los barcos que salían de puertos en los que se había declarado una epidemia (La Palma..., 31/08/1876: 2-3). En efecto, el Triunfo estaría libre de contagio y, a los pocos días, llegaría a Santa Cruz de La Palma. Esta situación de ida y vuelta entre los diferentes puertos que participan en el intercambio comercial y humano con Cuba nos muestra una intrincada red internacional, tejida en la segunda mitad del siglo XIX, donde Santa Cruz de La Palma desempeñaba un papel destacado.

El crecimiento de la red se puede observar fácilmente a medida que pasan los años. Ya a mediados de la década de los setenta, comenzamos a ver anuncios de pasajes en los diferentes números publicados, generalmente en la última página, que van ganando espacio a medida que se desarrolla la red migratoria. Algunos muestran los precios de los pasajes por clases, pero no será la tónica general, lo que no permite hacer un seguimiento, al menos a través de los periódicos, de los mismos $^{7}$. La realidad es que estos anuncios se fueron multiplicando a medida que la red de intercambios crecía: de aparecer solo un anuncio o ninguno, se pasó a que prácticamente todos los números de los periódicos llevaran, en su última página, hasta cuatro anuncios de compañías diferentes.

La ruta será desempeñada por multitud de barcos de diferente tipología. Algunos de los barcos que más aparecen, como el Rosario, la Verdad, el Fama

7 Lo cierto es que los pasajes de tercera habían pasado de costar 175 pesetas en 1862 a 100 a finales de la centuria (Hernández González 2005: 95), lo que sin ninguna duda, facilitaba el tránsito. 
de Canarias, el Triunfo o el María Luisa, serán barcos de fabricación palmera (Rodríguez Brito 1982: 94; De Paz Sánchez 2003: 228), anunciándose incluso la botadura de algunos (La Palma..., 19/04/1876: p. 1). Esta época coincide con el despegue del puerto santacrucero, en el cual no solo se situarán astilleros importantes, sino que también nacerán compañías marítimas que trasladen pasajeros y mercancías a través del Atlántico. En realidad, podría ser este uno de los condicionantes que limita la hostilidad hacia el fenómeno migratorio. El desarrollo de una actividad mercantil importante y la participación de algunas de las principales familias de Santa Cruz de La Palma en esa actividad hacen que se vea la emigración como un modelo de negocio y no tanto como una sangría que despuebla los campos de manos prestas para el trabajo.

\section{«Cebollas, pasajeros y otros frutos»}

El título de este epígrafe será una de las fórmulas más utilizadas por parte de los diferentes periódicos para expresar que en estos viajes hacia Cuba se cargaban pasajeros, pero también frutos con los que se comerciaba. También los buques que entraban en el puerto de Santa Cruz lo hacían pertrechados de "pasajeros y frutos coloniales». La ruta comercial era de ida y vuelta, y si bien la mayor parte de informaciones eran notas breves, se puede observar una considerable heterogeneidad tipológica.

En ese ir y venir de productos, estos no recibían el mismo trato minucioso que los pasajeros por parte de los periódicos. Si bien los pasajeros se intentaban cuantificar en numerosas ocasiones, no pasará así con los productos agrícolas o ganaderos ${ }^{8}$, los cuales, rara vez, se mencionarán explícitamente, destacando entre ellos solamente los cargamentos de cebollas.

La cebolla será uno de los cultivos de exportación esenciales en la Isla a finales del siglo xix. El desarrollo de este cultivo, al menos de manera considerable, había comenzado a mediados de siglo y se había desarrollado, principalmente, por gran parte de los terrenos de regadío de la Isla, aunque también hubo campos de cebollas en tierras de secano. Lugares como Los Sauces, Los Llanos de Aridane, Tazacorte o los alrededores de Santa Cruz de La Palma se convirtieron en grandes productores de este bulbo ${ }^{9}$. Grandes cantidades de cebollas salían en dirección a las Antillas españolas, donde su consumo era considerable (Rodríguez Brito: 1982: 136-137). Esta situación era percibida por los propios redactores de los periódicos palmeros, quienes hablaban de la necesidad de

8 No es lo más común, pero hay publicaciones con envíos de vacas para Cuba (El Eco..., 16/02/1885: 2).

9 Olivia Stone (1887: 326) ya había mencionado en su obra la profusión de cebollas en la zona noreste de la isla, principalmente en Los Sauces: «Whole fields are covered with onions, which grow plentifully, and being within reach of La Ciudad, they are easily carried thiter for export» [ «Campos enteros están cubiertos de cebollas, que crecen abundantemente, y al estar al alcance de La Ciudad, eran fácilmente transportados para su exportación»]. 
diversificar sus compradores, debido a la tremenda dependencia que el fruto tenía del mercado antillano en general, y cubano en particular ( $L a$ Palma..., 31/12/1877: 1).

Una parte considerable de las cargas para América no se embarcarán por el puerto de Santa Cruz, sino que se harán por pequeños puertos del norte de la Isla, como Puerto Espíndola, relativamente desarrollados en aquel entonces, ya que no solo se dedicaban a este comercio transatlántico, sino también a la comunicación por mar con otras poblaciones de la Isla (Batista Medina y Hernández López 2001: 279-284). Este tráfico comercial no solamente se producía de manera legal, sino que también dejaba abierta la puerta a cierto contrabando.

También tendrán amplia repercusión las cuestiones relativas al tabaco. Un cultivo en profundo ascenso en la Isla durante la segunda mitad del XIX, y sobre todo en el último cuarto. Por ello, recibirá mucha atención de las diferentes cabeceras (Rodríguez Concepción 2003: 71-83). La importancia del tabaco, más allá de que supone una de las principales actividades económicas de la isla en el período posterior a las tintóreas, es la relación que posee con Cuba, por eso atañe a este trabajo. El tabaco palmero siempre será referencia y el objetivo será competir con el que se produce en la Antilla. Las autoridades y agricultores palmeros buscarán igualarlo, al menos en lo que a calidad se refiere. Debido a ello, se ensalzarán las cualidades del mismo, recogiéndose y publicando cualquier reconocimiento que el tabaco palmero o canario reciban ${ }^{10}$. Siguiendo esa línea, algunas cabeceras defenderán a ultranza que se produzca, por parte de las autoridades, una apuesta decidida por la industria tabaquera canaria, que la sitúe al mismo nivel que la de Cuba (El Iris..., 07/01/1882: 1). Aunque ello quede fuera de la más estrecha relación La Palma-Cuba, los rotativos palmeros presentarán un interés marcado en publicar las diferentes noticias relacionadas con la política tabaquera de la administración del Estado. En cierta medida, se convertirán en voceros de la lucha de la industria tabaquera en la Isla.

En definitiva, observando la prensa palmera de finales del XIX, se pueden confirmar dos realidades. En primer lugar, que Cuba es omnipresente y, en segundo lugar, que el modelo económico de la isla de La Palma se desvía del que la historiografía generaliza para Canarias durante este período, con una agricultura de exportación basada en varios productos, destacando el incipiente plátano, la papa, el tomate, el azúcar y el tabaco. El modelo económico palmero de finales del siglo se basará en una triada nítida: puerto, cebollas y tabaco. Un modelo triangular que, a su vez, retroalimentará la primera de las conclusiones, ya que, indiscutiblemente, Cuba se encontrará en el otro extremo de esas actividades, ya sea por intercambio o por oposición.

10 «El tabaco alaborado [SIC] aquí casi puede compararse con el que se importa de la isla de Cuba: buen aroma, buen sabor, buen arder, todo revela lo que dejamos dicho» (La Palma..., 17/03/1882: 1). 


\section{La prensa y la transmisión de las ideas}

El intercambio de información de actualidad se producía de múltiples formas, principalmente a través de otros periódicos españoles, de telegramas, de cartas directas o a través del intercambio de cabeceras entre las dos islas. Muchos de los periódicos palmeros que se editaban en esta época tenían suscripciones para posibles clientes en Cuba y el extranjero. Cabeceras palmeras como $\mathrm{El}$ Criterio, El Fomento, El Grito del Pueblo o La Justicia reflejaban los precios de las suscripciones en sus portadas o contraportadas. De entre ese amplio número de cabeceras, destacaba La Asociación, cuyo precio en Cuba y Puerto Rico era menor que en el resto de países del extranjero, hecho que no era habitual en todas las cabeceras, pero que sí ocurría en este caso, mostrando con ello un cierto matiz.

La Asociación tendrá un vínculo especial con la Perla del Caribe, sin ninguna duda se venderá en Cuba y Puerto Rico, desde donde reciben noticias y corresponsalías varias (La Asociación..., 23/05/1879: 1). Este periódico, que se editó entre los años 1879 y 1882, presentará una profusión de cartas importantes que serán enviadas desde Cuba y que se publicarán íntegramente. Entre las mismas destacan algunas firmadas por Aridane ${ }^{11}$, uno de los seudónimos habitualmente utilizados por Gómez Wangüemert (De Paz Sánchez 1992: 181), así como de otros miembros de la burguesía palmera en Cuba. Así, también publicarán obras de personajes como Wenceslao Abreu, de quien difundirán algún poema (La Asociación..., 06/09/1882: 3).

Este tipo de informaciones "de vuelta» nos confirman que, al menos, una parte de la prensa palmera era leída en Cuba. Esto no solo se puede ver para La Asociación, también se observa para el brevísimo El Faro (Régulo Pérez 1948: 356), que, entre sus múltiples noticias, nos permite observar un cierto feedback con la comunidad canaria instalada en la Antilla (El Faro..., 23/03/1885: 2).

Desconocemos si esta dinámica se producía en la dirección contrario, es decir, desconocemos si los palmeros letrados que están en su isla estaban suscritos a algún periódico cubano. La lógica dicta que, muy probablemente, algún caso hubiera. Lo que sí podemos comprobar, a través de las cabeceras palmeras, es que los rotativos cubanos llegaban a La Palma. Las informaciones publicadas procedentes del habanero Diario de la Marina no serán extrañas aunque muchas lleguen a través de intermediarios. Aun así, muchos periódicos canarios tenían fuertes vínculos con la Antilla. El caso más claro será el de La Asociación, anteriormente mencionado, pero no será el único periódico que reciba homólogos cubanos; también La Patria (publicado entre 1883 y 1884) recibirá en su redacción varios diarios procedentes de la Antilla ${ }^{12}$.

11 Véanse, por ejemplo: La Asociación..., 01/08/1882: 1-2; La Asociación..., 16/08/1882: 2 o La Asociación..., 21/09/1882: 1-2.

12 Véanse, por ejemplo: La Patria..., 21/07/1883: 3; La Patria..., 29/07/1883: 3; La Patria..., 24/11/1883: 3 o La Patria..., 18/11/1884: 3. 
Muchos recibirán periódicos cubanos procedentes de otros lugares que no sean solamente la capital cubana. El rotativo La Palma recibirá y publicará fragmentos de El Centinela de La Habana (La Palma..., 16/01/1879: 1-2), pero se enorgullecerá también de recibir, en su redacción, algún número de El Progreso, publicado en la ciudad de Cárdenas (La Palma..., 01/05/1876: 2). Esta realidad muestra la profundidad del vínculo, los periódicos que se reciben se publicarán como adquisiciones valiosas y las noticias recibidas no solo se generarán en La Habana, sino que también se producirán en otras ciudades, como Pinar del Río, San Antonio de los Baños o Candelaria (La Asociación..., 12/06/1882: 4), lugares con una inmensa tradición de relación con la comunidad canaria (Hernández González 2005: 53-54 y 100).

Esa información cubana que llega también se canalizará a través de las herramientas de comunicación que emplea el asociacionismo canario en Cuba. El Eco de Canarias llegará a La Palma y será leído (Cabrera Déniz 2002: 220 223). Este periódico planteará una cuestión importante que matizará la visión de la mayor parte de la prensa palmera, ya que posee una actitud crítica con el proceso migratorio, aunque dicha crítica se enfocará más a las formas en las que se produce el fenómeno que a la emigración en sí misma. Esta información llegará fácilmente a los lectores palmeros, puesto que el Eco de Canarias arribará a gran parte de las redacciones de La Ciudad, mostrándonos en disposición de afirmar que tanto El Criterio como El Fomento - y, muy probablemente, también La Patria- tendrán ejemplares del mismo.

El Eco de Canarias fue una de las expresiones escritas de un asociacionismo canario en Cuba que nacería con el fin de auxiliar a paisanos en apuros y que experimentaría un período de auge a finales de la década de los setenta (Hernández González 2006-2007: 292-293). Dicho lo cual, las informaciones emanadas del trabajo y las actuaciones del asociacionismo canario en Cuba no solo llegaban a La Palma a través de esta vía, sino también a partir de otras menos convencionales, como los propios emigrantes retornados. Lo cierto es que, sea como fuere, las asociaciones canarias reciben gran atención, sobre todo cuando se producen envíos de dinero. Cuando hay tempestades y situaciones climáticas extraordinariamente adversas ${ }^{13}$, el asociacionismo canario no duda en actuar en beneficio del campo palmero, de la misma forma que los editores palmeros tampoco titubean a la hora de publicar estas actuaciones.

En definitiva, en cuanto a la información, nos encontramos con una situación que se asemeja a la cuestión migratoria, ya que la misma fluye entre las dos orillas con cierta naturalidad y sin grandes exaltaciones. Así es como debieron

13 Aunque para el período que nos ocupa no hemos podido ver casos de sequías importantes, Garrido Arbolafia (2002: 224-225) recoge una cita del periódico El Time para el año 1868 en el que dice que las clases populares de Puntagorda, perdidas las cosechas, se ven forzadas a "alimentarse de la raíza de helecho si es que esta no desaparecía también». Además, extrae de un libro de actas Puntallana, que para el año 1900 «ha entrado el pánico en la población [por la sequía] y que no se oye más que hablar de la emigración para las Américas». 
observarlo los palmeros coetáneos, al menos los residentes de La Ciudad. No solo hay un fuerte y perceptible trasvase de contenidos, de información en sí misma, sino también de continentes, como si la distancia fuera más geográfica que de cualquier otro tipo. En cierta medida, esto es solo una muestra más de la densidad del tejido creado entre las dos islas, así como de la sensación de que la pertenencia es, en cierta medida, bi-territorial.

\section{Relaciones en tiempos de conflicto}

Los hijos de las Canarias tenemos un doble motivo de alegría y de satisfacción al ver asegurada la paz de Cuba porque tanto se ha suspirado, pues aparte del interés general que como buenos españoles debe inspirarnos la terminación de la funesta lucha que la perla de las Antillas ha sido teatro, otro interés particular, nacido de un sentimiento no menos noble, regocija nuestro ánimo al contemplar terminada la asoladora guerra de Cuba; si la Palma es nuestro suelo natal, Cuba es para muchas familias de estas islas hogar querido; allí tenemos padres, hermanos y amigos; allí hay numerosos corazones que participan de nuestras alegrías lo mismo que de nuestros sinsabores, y un sentimiento análogo se despierta en nuestros pechos, alegrándonos con las prosperidades de aquel suelo lejano y entristeciéndonos con sus desgracias. (La Nueva Palma..., 23/07/1880: 1)

Con estas palabras de alegría y cercanía comunicaba el periódico La Nueva Palma, el fin del segundo conflicto armado cubano, aquel que la historiografía ha querido llamar como "Guerra Chiquita» y que apenas duraría unos meses entre los años 1879 y 1880 (Pérez Jr. 1983: 12-13; García Mora 2009: 329-330). Este supondría el estertor final del primer gran proceso de independencia, que había comenzado durante la guerra de los Diez Años.

Gran parte de los referentes de la comunidad canaria celebrarán el fin, a la postre temporal, de la insurrección. Al posicionamiento de la mayor parte de las redacciones de los periódicos palmeros, se unirá la Asociación Canaria en Cuba, que nombrará socios de honor a los generales Martínez Campos y José Pascual de Bonanza (La Palma..., 08/01/1879: 2). Informaciones que sin duda llegarán a La Palma.

Durante el período entre conflictos, los periódicos palmeros recogerán toda la dinámica parlamentaria (y extraparlamentaria) entre liberales y conservadores y, con especial atención, seguirán la cuestión cubana. En ese sentido, habrá un alineamiento ideológico casi total y acrítico: los periódicos de corte liberal apoyarán a los liberales, mientras que los de filiación más conservadora lo harán al partido correspondiente.

Esta realidad está en parte propiciada por el canal mayoritario por el que se recibían las noticias políticas. Si bien las informaciones ámbito de social e incluso las económicas tenían una procedencia más heterogénea, con un amplio componente de información directa, esto no solía ocurrir en el ámbito político, ya que estas, en su mayoría, llegaban a las redacciones palmeras a través de Madrid, facilitando así el acopio de información por fuentes afines y remarcando el sesgo ideológico. 
En esta dinámica política en período de paz, tres temas coparán las líneas de la información cubana en los periódicos palmeros: el comercio, la dinámica partidista en relación con la cuestión de la autonomía cubana y, por último, la esclavitud. Si bien los primeros temas no se salen de las dinámicas ya mencionadas, con respecto a la esclavitud, nos encontramos con una realmente curiosa tendencia general hacia la crítica durante el período de nuestro estudio en el que esta se encuentra vigente. Crítica encabezada, sin ninguna duda, por La Asociación, muy beligerante contra la cuestión ${ }^{14}$.

Más allá de cuestiones de la dinámica partidista colonial, una nueva sacudida bélica se produjo en el año 1895 con la reapertura de un conflicto abierto entre fuerzas independentistas y la autoridad colonial. El nuevo conflicto, lógicamente, afectó a la dinámica periodística palmera, la cual aumentó el ya notable espacio que dedicaba en sus números a las cuestiones cubanas.

«Nadie ignoraba lo que se venía preparando en Cuba...» afirmaba El Noticiero (28/03/1895: 3), según ellos, el nuevo estallido bélico no era impredecible, mucho menos para los que se encontraban tan vinculados a la información que procedía de la isla. Inmediatamente después del estallido de la guerra, los diferentes periódicos comenzaron a publicar noticias sobre las vicisitudes del mismo, las cuales llegaban por diferentes vías (directa, telégrafos, otros periódicos, etc.). Algunas cabeceras, como El Adalid, le dedicarán al conflicto incluso una sección completa durante gran parte de la contienda ${ }^{15}$.

Ese denso pero difuso intercambio de información hacía que estas noticias no siempre fueran verídicas. Un caso curioso es el de Antonio Maceo, líder insurreccional cubano que caería en el campo de batalla, cerca de La Habana, el 7 de diciembre de 1896 (Helg 1999: 256), al cual la prensa palmera ya había matado con antelación en más de una ocasión (El Noticiero..., 01/05/1895: 3). Tampoco las informaciones estarán exentas de un marcado sesgo partidista que donde mejor se reflejaba era en el apoyo a los diferentes generales al mando. Mientras que las cabeceras liberales apoyaban a Martínez Campos, los conservadores lo criticaban y defendían la gestión de Valeriano Weyler. Esta realidad también era extensible hacia la cuestión de la institucionalidad de Cuba, aunque con más amplios matices. La mayor parte de las cabeceras palmeras habían defendido la legitimidad del autonomismo, principalmente de manera previa a que se desencadenara el conflicto, cuando hay una mayoría considerable sobre la necesidad de la reforma. Algunos rotativos como El Adalid incluso llegaron a defender que las posibles reformas que debían realizarse en Cuba y Puerto Rico serían buenas para La Palma ${ }^{16}$. Aunque no serán muchos, otros periódicos se mostrarán contrarios a una reorganización que le diera mayor

14 Como muestra puede verse La Asociación..., 18/01/1880: 2.

15 Para muestra pueden verse El Adalid..., 28/12/1895: 3 o El Adalid..., 12/10/1895: 2-3.

16 Para muestra puede verse el siguiente artículo: «Sagasta firme» (El Adalid..., 09/03/1895: 3), o el número del mismo periódico correspondiente 17 de noviembre de 1894, donde aparecen varias secciones hablando en el mismo sentido. 
autonomía a la Antilla. Encabezados por El País (03/08/1897: 1), quizás el más conservador de todos los periódicos estudiados, algunas opiniones observaban en la petición de autonomía solo una excusa previa para la independencia. En definitiva, la contienda discursiva entre si la autonomía era la solución a las legítimas aspiraciones cubanas o solo el paso justamente anterior a la ruptura del nexo colonial estaba servida.

En cierta medida, durante la guerra de Cuba se produjo la repetición de un esquema discursivo nacionalista bastante común en este tipo de conflictos. Los soldados que iban a la guerra eran héroes que se jugaban la vida por la patria, los insurrectos cubanos, unos bandidos o desagradecidos y los estadounidenses, unos ambiciosos y/o codiciosos. La desviación de esta tendencia discursiva básica solo se produce a través de matices o de elementos concretos, algunos de los cuales serán muy llamativos, como es el caso del periódico La Justicia (19/11/1898: 1), que critica que los ricos no vayan a la guerra, mientras que los pobres sí que lo hacen. Esto era una realidad incontestable. A pesar de la obligatoriedad del servicio militar, las familias adineradas no enviaban a sus hijos utilizando mecanismos legales como la redención en metálico o la sustitución (Sánchez Abadía 2001: 116-117). Dicha realidad dejaba la recluta para Cuba en un ejército de soldados de clases bajas.

En cuanto a los estadounidenses, estos, principalmente gobernantes y generales, serán objeto de críticas y burlas en las páginas de la mayoría de los periódicos, incluso antes de entrar en la guerra (El Grito del Pueblo..., 30/05/1897: 1; El Pancista..., 20/06/1898: 1), aunque la beligerancia de los diarios palmeros no tendrá el grado que muestran otros territorios del Archipiélago (Luis León 2015: 14-18). De esta tendencia probablemente solo se desmarcará El Zurriago, que en un durísimo artículo sí que definirá a los norteamericanos como «asesinos» y como una «raza inhumana» (El Zurriago..., 24/04/1898: 3).

El dolor será profundo por la pérdida de Cuba, pero no reflejará, al contrario que en el caso de Tenerife, un temor atroz a la pérdida de la soberanía española o a una hipotética venta. En el aire mediático palmero no se respira esa sensación de tragedia inminente, que sí se puede encontrar fácilmente en la otra isla (Luis León 2015: 19). Lo que sí se observará es una reedición de los mensajes enviados tras el fin de los conflictos cubanos anteriores, a la hora de mostrar el vínculo especial que La Palma tenía con Cuba, siendo esta no solo una pérdida patriótica, sino también palpable en el día a día de los palmeros.

A pesar del fuerte vínculo existente, ya algunas cabeceras palmeras habían intentado delimitar, de manera temprana, que los territorios españoles del Caribe y el Pacífico no eran lo mismo que Canarias, y que estas no eran un territorio colonial (El Noticiero..., 09/05/1895: 2). Este discurso buscaba establecer una relación de pertenencia más estrecha a la patria que disipara cualquier duda sobre la españolidad de Canarias.

La historiografía ha demostrado que el cambio de estatus de Cuba no acabó con la corriente migratoria que existía desde Canarias hacia la Antilla, y mucho 
menos desde La Palma (Macías Hernández 1888: 190-194; Hernández González y Hernández García 1993: 557-582). La cuestión que convendría plantearse es la de saber si durante el conflicto hay un cambio en la relación. La lógica a priori podría dictar que sí, y algunos periódicos así lo reflejarán. El País, por ejemplo, incidía, a los pocos meses de terminar la guerra, en que «el mal estado de Cuba» era una de las causas principales de los problemas de la economía palmera ( $E l$ País..., 18/05/1899: 1). No estamos en disposición de negar rotundamente esta afirmación, pero sí de ponerla en tela de juicio o, al menos, de matizarla. En primer lugar, no se observan grandes variaciones en los anuncios de tráfico marítimo que se produce entre La Palma y la Antilla. En realidad, mientras el conflicto es simplemente hispano-cubano, no se producen apenas diferencias. Los barcos siguen saliendo de La Habana y de Santa Cruz de La Palma cargados de pasajeros y de frutos en dirección a los dos lados. La situación cambia un poco cuando los Estados Unidos entran en la guerra, pero, aun así, las consecuencias tardan unas semanas en hacerse palpables. Tenemos rastreados anuncios de partidas de barcos de manera ininterrumpida hasta los últimos días de mayo de 1898, más de un mes y medio después del bombardeo de Matanzas. Otra cuestión interesante es cuánto dura ese parón, puesto que a principios de septiembre ya se publican noticias y anuncios acerca de la reanudación de los viajes. Por lo que podríamos estar hablando, prácticamente, de apenas un verano de desconexión.

En definitiva, lo que se puede observar es que la guerra, en todas sus etapas, supone un inevitable cambio en la relación entre los dos territorios y que es evidente que la situación en Cuba mantiene en vilo a los periódicos palmeros por diferentes motivos (humanos, económicos, patrióticos, etc.), pero no es menos cierto que el período de desconexión es pequeño y que las consecuencias en la relación serán menores de las que podría haber generado una sacudida de este calado. Ello es incluso más sorprendente que una dependencia total que suponga una crisis profunda, porque lo que muestra en realidad es que la vinculación es tan fuerte que ni siquiera un conflicto bélico, una ruptura nacional, ni una ocupación por un tercero acaban con una relación tan profunda y estrecha.

\section{La relación con otros países}

Las publicaciones palmeras no solo se hacían eco de las noticias que procedían de Cuba, también lo hacían de otras procedentes del resto de territorios americanos. Dicho lo cual, la diferencia cuantitativa entre las noticias que trataban acerca de Cuba y sobre el resto de Hispanoamérica era abismal. Aun sumando todos los territorios de la región, la diferencia de noticias relevantes que aparecen supera ampliamente la proporción de seis a uno en favor de Cuba, lo cual es un dato que habla aún más de la importancia que los rotativos palmeros le otorgaban a las informaciones que llegaban desde la Antilla. La mayor parte de las noticias relativas a este grupo de países quedará relegado a un segundo plano con respecto a lo que se ha podido observar para Cuba. Dichas noticias ocuparán noticias breves, principalmente, llegando a 
ocupar espacios más notables, pero aun de segundo orden, cuando la enjundia de la noticia resulta algo más considerable.

En ese amplio y heterogéneo grupo de países incluiremos también a Puerto Rico. Ello es debido a que, a pesar de que este territorio será parte de España hasta 1898, la mayor parte de la emigración palmera irá a Cuba en esta época ${ }^{17}$. Puerto Rico quedará entonces como un lugar de segundo orden migratorio, comercial y en cuanto a noticias del conflicto bélico.

Habrá noticias y anuncios de barcos que hacen escala en San Juan, pero no serán la mayoría, y de las escasas informaciones que se publican con respecto a Borinquén, aún menos serán de contenido único sobre el país. Entre los pocos ejemplos rastreables está la salida del buque Celaje, el cual partirá cargado de frutos palmeros, con destino a la capital puertorriqueña y previa escala en Tazacorte (La Palma..., 02/05/1877: 2). La guerra también atraerá algo de información, pero el lógico desbalance hacia Cuba será bastante notorio ${ }^{18}$. La mayor parte de las informaciones tendrán que ver con desastres naturales: terremotos, huracanes e inundaciones, aunque sean locales. Si bien es cierto que aparecen noticias sobre estos acontecimientos meteorológicos o geológicos, estos no se publicarán con la misma frecuencia que para Cuba (incluso algunas informaciones serán para ambas islas). La realidad es que, en este caso, la publicación de noticias estará más justificadas por su condición de suceso llamativo acaecido en un territorio español que por el hecho de afectar directamente a la comunidad canaria que reside en esos lugares.

La República Dominicana será un territorio del que también se hablará poco. A pesar de haber pertenecido efímeramente a España durante varios años en la década de los sesenta (Hertel 2016), y de tener una posición geográfica muy cercana a los territorios hispanos del entorno del Caribe, no se produce una profusión de noticias. Lo único reseñable es tal vez alguna escala en Sabaná del velero Triunfo en dirección a La Palma (La Palma..., 13/04/1879: 3) y una sorprendente noticia publicada en El Eco, en el año 1884, en la que se habla de las bondades de la emigración a este territorio (El Eco..., 18/12/1884: 2), lo cual, como se podrá observar más adelante, resultará una anomalía. En definitiva, se

17 Julio Hernández García (1981: 178-203) escribe que más de un 97\% de las comendaticias de salida expedidas por la alcaldía de Santa Cruz de La Palma, entre 1848 y 1898, reflejarán como destino Cuba. Los datos que presentan los ayuntamientos de El Paso y Mazo, para similares segmentos temporales, serán aún mayores. Además, los que registros de estos dos ayuntamientos que no muestran a Cuba como destino, no especificarán un destino final, siendo éste una incógnita.

18 Los conflictos de independencia de finales del siglo XIX no solo se restringen a Cuba, sino que afectarán también a otros territorios como Filipinas y Puerto Rico. Entre las publicaciones palmeras, algunos como el Diario de Avisos, El Grito del Pueblo y, sobre todo, El País recogerán noticias tanto de la situación en la pequeña isla caribeña como en el archipiélago del Pacífico, pero su profusión será mucho menor comparado a las que proceden de Cuba, es más, las noticias relativas a Filipinas se publicarán ligeramente más que las de Puerto Rico. 
cree que esta desconexión mediática puede estar propiciada por el escaso vínculo migratorio existente entre los dos territorios, lo que hacía que la información no fluyera a pesar de la relativa cercanía a Cuba.

Las corrientes migratorias y, sobre todo, comerciales no se restringirán a las grandes Antillas, habrá migración y comercio hacia otras zonas del continente. El Río de la Plata, un lugar de emigración no tan extraño durante el siglo XIX para canarios de otras islas, presentará alguna noticia, aunque serán escasas. Entre las más llamativas se encuentra una publicación judicial que compete a emigrantes y familiares. El Iris publica la resolución de un pleito entre dos vecinos de Las Breñas (uno de Breña Alta y otro de Breña Baja) que en ese momento se encuentran emigrados en Argentina (El Iris..., 16/10/1880: 2). Esta situación encaja perfectamente con la casuística de las herencias vacías y otros pleitos legales, que hemos podido observar anteriormente para el caso cubano.

Llegados a este punto nos encontramos con una curiosidad bastante llamativa: la mayoría de cabeceras que se pronuncian acerca de la emigración americana, con La Palma a la cabeza, lo harán desaconsejándola. Este periódico publicará varias informaciones sobre la emigración hacia Costa Rica ${ }^{19}$, pero, en el fondo, para ellos, este no será el destino ideal (La Palma..., 01/11/1878: 1-2; La Palma..., 21/06/1879: 2-3). Ese posicionamiento se agudizará aún más en el caso de la emigración hacia México, país al que desaconseja ir a sus paisanos, recomendando en su lugar la migración hacia Cuba (La Palma..., 09/12/1877: 2). En definitiva, estos periódicos no querrán que los emigrantes vayan «al extranjero» y por ello primarán los aspectos negativos, prefiriendo y promoviendo una migración ordenada hacia Cuba.

Pero si un país sigue a Cuba en atención por parte de los medios escritos en La Palma ese será Venezuela. Venezuela será importante porque será el destino preferido por la mayor parte de los prófugos canarios que buscaban eludir el servicio militar, principal motivación de la emigración clandestina en esta época (Hernández García 1981: 277-288). Si bien Cuba será el único territorio del que se publiquen tres tipos de noticias: ordinarias (salida de barcos y pasajes), extraordinarias (sucesos meteorológicos, anécdotas, etc.) y política, Venezuela será el único de los otros territorios americanos que combine noticias ordinarias con extraordinarias. Las hojas de los periódicos palmeros publicarán anuncios de buques que salen en dirección al puerto de La Guaira, así como de pasajes para tomarlos. En muchos de estos navíos irán como polizones aquellos que querían eludir el servicio militar. De todos los navíos que realizan la carrera de América, el más repetido para este trayecto será precisamente el bergantín Matanzas, cuyas salidas serán anunciadas en La Patria, El Faro o El Fomento. A pesar de ello, frente a la posibilidad de emigrar hacia Venezuela, también se

19 Durante los gobiernos del general Tomás Guardia (1870-1876 y 1877-1882) se intentó fomentar la emigración de españoles hacia Costa Rica a través de vías diplomáticas y de la publicidad. En esta migración participaron canarios, entre otros españoles, que se dedicaron al trabajo agrícola (González Chaves 2017: 135-136). 
mantiene la idea de que es mejor emigrar a Cuba. Por ello, La Palma publica en el verano de 1876 un texto sobre el retorno de tinerfeños a su tierra natal desde Venezuela, puesto que «no encontraron en aquel país la fortuna prometida» ( $\mathrm{La}$ Palma..., 24/06/1876: 2). También se publicarán noticias acerca de calamidades como enfermedades y se aportará datos sobre el intercambio humano y comercial, en muchas ocasiones contradictorios. Entre los textos que tienen como objetivo central hablar de Venezuela, destaca un especial dedicado por $E l$ $E c o$, que recogerá, en tres números diferentes, un anuario estadístico del país ${ }^{20}$. En definitiva, Venezuela será el país que más atención obtenga comparado con el resto de los territorios del continente. Esto ocurrirá porque se es consciente de la corriente existente, lo cual será fácilmente perceptible debido a la profusión de datos. Dicho lo cual, la diferencia, tanto cualitativa como principalmente cuantitativa con respecto al lugar central de interés de la prensa palmera, la isla de Cuba, será realmente grande.

\section{Conclusiones}

Resulta complejo establecer una serie de conclusiones que sean algo más que la recapitulación del conjunto de cuestiones que quedan explicitadas durante el cuerpo del trabajo, aun así, es necesario realizar dicha recapitulación. La primera de ellas es reafirmar la idea ya defendida por la mayor parte de la historiografía canaria de que La Palma es la isla más conectada con Cuba en este período de la contemporaneidad, lo cual no es un hecho rupturista, ya que es algo que queda claro, incluso, en el sentir popular del presente histórico. Dicho lo cual, hay que abundar en el criterio de la densidad de esta relación.

La conclusión principal de este trabajo es que La Palma, a finales del siglo XIX, será una entidad territorial conectada con el mundo exterior a través de Cuba, entendido "mundo exterior" como todo lo que sea fuera de las islas Canarias. Cuba desempeñará el papel de catalizador de la mayor parte de la actividad económica, humana e informativa que se produce en la isla de La Palma. Su papel como destino último o como generador de actividad es el que hace que se conecte con otros lugares de la geografía española (Galicia, Andalucía, Madrid, etc.) y extranjera (Venezuela, Nueva York, Puerto Rico, etc.) a través de redes de transporte e información que resultan necesarias para tejer la comunicación entre Cuba y La Palma.

En cierta medida, esta relación estrecha produce un continuo La PalmaCuba que trasciende la especialización económica y las clases sociales. Este vínculo nos permite afirmar que hay tanta o más relación directa entre Cuba y La Palma en esta época que con algunas de las islas del propio Archipiélago (por ejemplo, las islas periféricas de la provincia oriental). En cierta medida, la Antilla será considerada un lugar más del territorio, sin apenas diferencias. Estas solo

20 Véanse: El Eco..., 18/07/1885: 1; El Eco..., 24/07/1885: 2 o El Eco..., 02/08/1885: 1-2. 
aparecerán tímidamente cuando interese reflejar el estatus de Canarias como parte indisoluble de la Corona española.

Esta relación solo se produce con Cuba, la cual se separa ideológicamente del resto de territorios americanos (incluido Puerto Rico) en una tendencia creciente a medida que avanza la cronología de estudio. Si se observa con detenimiento, la mayoría de las referencias hemerográficas que se proponen sobre otros países son tempranas (excepto para la inevitable cuestión de la guerra), lo cual nos lleva a afirmar que no solo hay un enfoque directamente sobre la Antilla, más allá de su realidad geográfica, sino que, además, ese enfoque diferenciado va en aumento a medida que tiempo avanza.

Para finalizar, sería interesante plantear una idea que se esbozó en la introducción y que no es otra que la insularización de las dinámicas históricas. Este tipo de estudio quiere ser un punto de partida para análisis que profundicen en aspectos históricamente generalizados en exceso, como la actividad comercial, y plantear la necesidad de acercar el zoom hacia entidades territoriales, pero también humanas, que se desmarcan de la realidad general del Archipiélago.

\section{Bibliografía}

Almuiña Fernández C., 1977, La prensa vallisoletana durante el siglo XIX, tomo II, Valladolid, Diputación Provincial de Valladolid.

Baldacchino G., 2006, «Islands, Island Studies, Island Studies Journal», Islands Studies Journal, n. ${ }^{\circ}$, vol. 1, p. 3-18.

Batista Medina J.A. y Hernández López N., 2001, San Andrés y Sauces... una mirada a su pasado..., San Andrés y Sauces, Ayuntamiento de San Andrés y Sauces, Caja General de Ahorros de Canarias.

Cabrera Déniz G.J., 2002, «En torno a la prensa canaria en Cuba», Tebeto. Anuario del Archivo Histórico Insular de Fuerteventura, n. ${ }^{\circ}$ 15, p. 213-232.

De Paz M. y Hernández M., 1993, La esclavitud blanca. Contribución a la historia del emigrante canario en América. Siglo XIX, Santa Cruz de Tenerife, Cabildo Insular de Fuerteventura, Centro de la Cultura Popular Canaria, «Taller de Historia».

De Paz Sánchez M., 1991, Wangüemert y Cuba, tomo I, Santa Cruz de Tenerife, Centro de la Cultura Popular Canaria, «Taller de Historia».

De Paz Sánchez M., 1992, Wangüemert y Cuba, tomo II, Santa Cruz de Tenerife, Centro de la Cultura Popular Canaria, «Taller de Historia».

De Paz Sánchez M., 2003, La ciudad. Una historia ilustrada de Santa Cruz de La Palma, Santa Cruz de Tenerife, Ayuntamiento de Santa Cruz de La Palma, Centro de la Cultura Popular Canaria, «Taller de Historia».

García Mora L.M., 2009, «Un nuevo orden colonial: del Zanjón al Baire, 18781898», in Naranjo Orovio, C. (coord.), Historia de las Antillas, volumen I: Historia de Cuba, Madrid, CSIC., Ediciones Doce Calles, p. 303-337. 
Garrido Arbolafia M., 2002, La Puntallana: historia de un pueblo agrícola, Puntallana, Ayuntamiento de Puntallana, Caja General de Ahorros de Canarias.

González Chaves D., 2017, «Migración e identidad cultural en Costa Rica (18401940)», Revista de Ciencias Sociales, n. ${ }^{\circ}$ 155, p. 131-144.

González Pérez T., 1996, «Alfabetismo y escolarización en Canarias», Tebeto. Anuario del Archivo Histórico Insular de Fuerteventura, n. ${ }^{\circ}$ 9, p. 319-342.

Helg A., 1999, «La Mejorana y la independencia cubana: un choque de ideas y liderazgo entre José Martí y Antonio Maceo», Cuadernos de historia contemporánea, n. ${ }^{\circ} 21$, p. 227-258.

Hernández García J., 1981, La emigración de las Islas Canarias en el siglo XIX, Las Palmas de Gran Canaria, Cabildo de Gran Canaria.

Hernández González M., 2005, La emigración canaria a América, Santa Cruz de Tenerife, Centro de la Cultura Popular Canaria. Gobierno de Canarias.

Hernández González M., 2006-2007, «La prensa y el asociacionismo canario en América», Anuario americanista europeo, nros. 4-5, p. 289-315.

Hernández González M. y Hernández García J., 1993, «La emigración canaria a Cuba durante la ocupación norteamericana (1898-1902)», Anuario de estudios atlánticos, n. ${ }^{\circ} 39$, p. 557-582.

Hertel P., 2016, «La reanexión de Santo Domingo por España en 1861-1865. Sus circunstancias y consecuencias», in Opatrný J. (coord.), Proyectos políticos y culturales en las realidades caribeñas de los siglos XIX y XX, Praga, Editorial Karolinum, Universidad Carolina de Praga, p. 183-194.

Luis León A.D., 2015, «La imagen de América en la prensa del norte de Tenerife a finales del siglo XIX», Anuario de estudios atlánticos, n. ${ }^{\circ}$ 61, p. 1-22.

Macías Hernández A., 1988, «Un siglo de emigración canaria, 1830-1930», in Sánchez Albornoz (Comp.), Españoles hacia América: la emigración en masa, 1880-1930, Madrid, Alianza, p. 166-204.

Pérez Hernández J.E., 2003, «Entre el ideal y la realidad. Discurso de la modernización y devenir económico en La Palma (1850-1900)», Boletín Millares Carlo, n. ${ }^{\circ} 22$, p. 69-92.

Pérez Jiménez R., 2015, "La llegada del telégrafo a Canarias», Revista de la Academia Canaria de Ciencias, vol. 27, n. ${ }^{\circ}$ 2, p. 141-156.

Pérez Jr. L.A., 1983, Cuba Between Empires, 1878-1902, Pittsburgh, University of Pittsburgh Press.

Régulo Pérez J., 1948, «Los periódicos en la isla de La Palma», Revista de Historia, n. ${ }^{\circ} 84$, p. 338-413.

Rodríguez Brito W., 1982, La agricultura en la isla de La Palma, La Laguna, Instituto de Estudios Canarios.

Rodríguez Concepción A., 2003, La Tradición Insular del Tabaco, [Islas Canarias], Consejería de Agricultura, Ganadería, Pesca y Alimentación, Gobierno de Canarias. 
Sánchez Abadía S., 2001, "Olvidos de una guerra: el coste humano y económico de la independencia (Cuba-España, 1895-1898)», Revista de Indias, vol. LXI, n. ${ }^{\circ} 221$, p. 113-140.

Stone O., 1887, Tenerife and its six satellites, vol. I, London, Marcus Ward \& Co.

Fuentes hemerogáficas citadas

La Asociación: periódico político independiente, Santa Cruz de La Palma, 18791882.

La Justicia, Santa Cruz de La Palma, 1898-1899.

La Nueva Palma. Periódico político y de intereses generales, Santa Cruz de La Palma, 1880.

La Palma, Periódico imparcial de noticias e intereses generales, Santa Cruz de La Palma, 1876-1879, 1882.

La Patria. Periódico de intereses generales, Santa Cruz de La Palma, 1883-1884.

El Adalid. Periódico político y de intereses generales, Santa Cruz de La Palma, 1895.

El Eco: periódico político liberal, Santa Cruz de La Palma, 1884-1885.

El Faro. Periódico político y de intereses generales, Santa Cruz de La Palma, 1885.

El Fomento. Diario Liberal, Santa Cruz de La Palma, 1887.

El Grito del Pueblo: semanario político y de intereses generales, 1897.

El Iris. Periódico semanal de intereses generales, Santa Cruz de La Palma, 18801882.

El Noticiero, Santa Cruz de La Palma, 1895.

El País. Periódico político y de intereses generales, Santa Cruz de La Palma, 1897, 1899.

El Pancista, Santa Cruz de La Palma, 1898.

El Zurriago. Semanario de intereses generales, satírico y literario, Santa Cruz de La Palma, 1898. 